\title{
Epidemiological and Clinical Aspects of Scorpion Stings in Kurdistan Region of Iraq
}

\author{
Fenik Sh. Hussen*, Sherwan T. Ahmed \\ Department of Biology, College of Science, Salahaddin University-Erbil, Kurdistan Region, Iraq
}

Received: 12 March 2020

Accepted: 25 May 2020

\begin{abstract}
Scorpion sting is still a heath problem and a serious issue threatening public health in many countries of the world including Kurdistan-region of Iraq. The current study aimed to find out the spatial distribution of scorpion stings and their clinical features in the north region of Iraq. It could be mentioned that the present research work is the first comprehensive attempt to highlight the epidemiological aspects of scorpionism and clinical manifestations of individuals bitten by scorpions in Iraq. To meet the requirements of the survey and epidemiological pattern, all the cases $(n=4162)$ of scorpion stings that attended the primary health care centers and clinics from January 1, 2017 to December 31, 2018 in Erbil, Duhok and Sulaymaniyah provinces were considered. Moreover, the monthly frequency of scorpion stings at the provincial level were perceived and exploited for epidemiological mapping. However, scorpion envenomation is a neurotoxic syndrome, but other disorders such as cardiac failure, acute pulmonary edema, shock and death can occur. Fortunately, most of the scorpion stings in adults in Kurdistan-region of Iraq are deemed mild envenomation. Having said severe cases with highly systematic envenomation was reported in Erbil province during the study period. At the study time, $41 \%$ of the cases were found in Erbil followed by Duhok (34\%) and Sulaymaniyah (25\%), and the scorpionenvenomed individuals aged 15-49 years. Regarding seasonal variations, the peak of scorpion stings was elevated in June, July and August, whilst lowered in January and February. On the other hand, the highest scorpion stings were recorded in 2017 as compared to 2018. Based on the results, it has been concluded that scorpionism is a dangerous health dilemma in Kurdistan-region of Iraq with a high risk level of scorpion envenomation during summer season in the area.
\end{abstract}

Keywords: scorpion, distribution, sting, venom, health problem

\section{Introduction}

Scorpions are venomous arthropods and considered as one of the oldest arthropods because of their general characteristics and morphology that have not

*e-mail: fenik.hussen@su.edu.krd been changed much from their ancestors. Remains of scorpions were detected in fossils aged nearly 400 million years old [1]. Scorpion measurement boundaries are from 1.3 to $7.2 \mathrm{~cm}$, and they are easily identifiable owing to their morphological structures. The abdomen is composed of 12 different segments; the last five segments constitute the tail (metasoma). At the end of metasoma, there is a system specialized in injecting 
venom to victims. The system embraces the venom gland and a pointed aculeus called telson [2]. Scorpions which are nocturnal animals, hide under objects at day time and start to wandering on outward at dusk and night to prey their victims [3]. Scorpion poisoning is a great menace to the dwelling persons in tropical and sub-tropical regions posing severe complications such as death in some patients. It is noteworthy to mention that occasional deaths are well documented and most often occur in children $[4,5]$. In the last decades, the number of events caused by scorpion stings and consequent deaths have significantly been escalated in the world and almost more than 1200000 scorpion stings happen every year [6]. Scorpion envenomation is vigorously associated with neurotoxicity along with local and systemic effects. Usually, immediate local pain occurs which dissimulates to the adjacent anatomical areas. Discrete edema may be found at the sting site and sometimes the location of scorpion sting appeared $[5,7]$. Basically, the toxic impacts of Scorpion envenomation are attributed to the massive release of sympathetic and parasympathetic neurotransmitters [8], while the seriousness of the sickness is associated with cardiac and hemodynamic changes accompanied by cardiac shock and pulmonary edema leading to the death [9]. Among 1500 classified scorpions [7, 10], approximately 50 poisonous scorpion species live in the Middle East. Many poisonous scorpion species are dwelling in Iraq because of the favorable geographical and climatic conditions [11]. Previously published research articles recorded five families of scorpions in Iraq which are Buthidae, Euscorpiidae, Hemiscorpiidae, Iuridae and Scorpionidae. The most dangerous species belong to the families, Buthidae and Hemiscorpiidae [3, 12-16]. Turning the envenomation by these arachnids is one of the envenoming of highest sanitary impact in Kurdistan region of Iraq [15]. One of the most hazardous scorpion in the region is the black scorpion, A. crassicauda, that can be responsible for severe envenomation [17].

This study intended to describe the incidence, geographic locations and clinical aspects of scorpion stings in the north part of Iraq. The collected data are significant for controlling and managing scorpion distribution, pattern, and stinging in areas underwent the survey. Since scorpion stings are a public health threat in the aforementioned provinces, hence, conducting studies in this domain is inevitable. This manuscript is a descriptive and retrospective study based on the data extracted from the health center files of three provinces in the north of Iraq over two years.

\section{Material and Methods}

\section{Study Area}

Kurdistan region is a mountainous land locates where Syria, Turkey and Iran meet. It has chains of high mountains such as Toros and Zagros mountains, which a pair of high arch of about 3000-4000 meters' altitude. Boundaries of Iraqi Kurdistan extend from a longitude $4215^{\circ} \mathrm{E}$ to $4730^{\circ} \mathrm{E}$ and from latitude $3425^{\circ} \mathrm{N}$ to $3750^{\circ} \mathrm{N}$ and covers an area of approximately 165000 square kilometers (Fig. 1). Kurdistan is bounded to the north by Toros Mountain in Turkey, to the North West by Syrian, and to the southwest, and south by Hamreen mountain of Iraq [18]. This region embraces three main provinces (Erbil, Duhok, and Sulaymaniyah). These provinces face some extreme climate, in winter the weather is colder with snowfall in the high mountains, precipitation and relative humidity are maximum, temperature and evaporation are minimal. Temperature and evaporation are highest in the summer, hot and dry season while the relative humidity is low. The average annual precipitation is between around 450 and $1000 \mathrm{~mm}$; temperatures vary from $-5^{\circ} \mathrm{C}$ in winter to $48^{\circ} \mathrm{C}$ in summer over a wide range.

\section{Data Collection}

The presented mentioned data were collected from public health offices of Erbil, Duhok, and Sulaymaniyah provinces. Documents related to scorpion stings in 2017 and 2018 were reviewed. Scorpion sting data were extracted from the victim records including age, sex, location of sting on the body, sting time (monthly cases), systematic symptoms, received treatments and geographical locations of scorpion stings.

\section{Statistical Analysis}

Graph Pad-Prism (version 7) was used to analyze and calculate the significant difference among data values, and then calculated employing Chi-squared

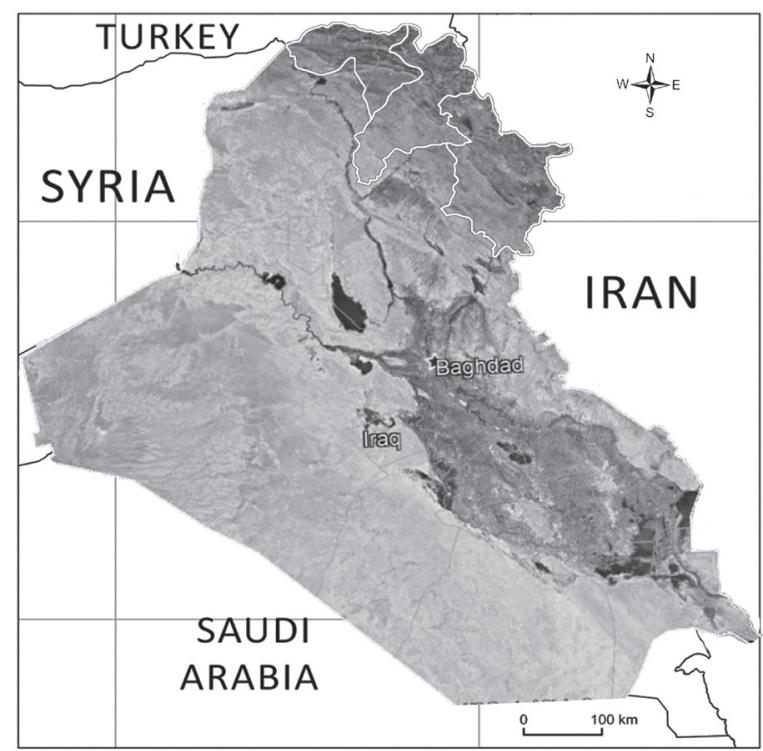

Fig. 1. Map of study area, Kurdistan-Iraq with the three provenance Erbil, Duhok and Sulaymaniyah, marked in white. 
Table 1. Scorpion sting during 2017 and 2018 in three cities of north of Iraq.

\begin{tabular}{|c|c|c|c|}
\hline City & 2017 & 2018 & Total \\
\hline Erbil & 745 & 916 & 1661 \\
\hline Duhok & 575 & 850 & 1425 \\
\hline Sulaymaniyah & 441 & 635 & 1076 \\
\hline Total & 1761 & 2401 & 4162 \\
\hline
\end{tabular}

test. References were adjusted through EndNote X7 program.

\section{Results}

Roughly, 4162 cases of scorpion- stung patients presented at the public hospitals in the aforementioned provinces of Kurdistan region, Iraq from January, 2017 to the end of December, 2018. In 2017, about 1761 cases of scorpionism were attended the public hospitals. It would be less than the number of cases (2401) in 2018. The frequency of stung cases was higher in Erbil city (41\%) as compared to the cities; Duhok $(34 \%)$ and Sulaymaniyah (25\%) (Table 1). After their treatment at the emergency department, all cases of scorpion stings were transferred to the local hospital for further management. Children under 10 years were admitted to the emergency room for one day, while older patients were examined for three hours and secondary symptoms such as difficulty in breathing, muscle twitching or thrashing, vomiting, hypertension, headache were observed. Most of the patients (92\%) were experiencing primary symptoms such as swelling, redness and inflammation at the site of sting and about $7 \%$ of cases suffered from systematic toxicity; arterial hypertension, tachycardia and myalgia. Most of them treated with anti-venom injection except one case had highly systematic envenomation in Erbil province at the study time. Luckily, no mortality reported during the study period. Most of the venomous scorpions, described by the patients who attended the hospital, were black and yellow in colour. It should be mentioned that the health professionals in the province hospitals have lack of experience in recognizing and classifying

Table 2. Frequency of scorpion stings according to gender groups in Erbil, Duhok and Sulaymaniyah during 2017-2018.

\begin{tabular}{|c|c|c|c|c|}
\hline \multirow{2}{*}{ City } & \multicolumn{2}{|c|}{2017} & \multicolumn{2}{c|}{2018} \\
\cline { 2 - 5 } & Male & Female & Male & Female \\
\hline Erbil & 350 & 395 & 516 & 400 \\
\hline Duhok & 309 & 266 & 450 & 400 \\
\hline Sulaymaniyah & 240 & 201 & 366 & 269 \\
\hline Total & 899 & 862 & 1332 & 1069 \\
\hline
\end{tabular}

venomous scorpions, so this study has become the first epidemiological report about scorpion stings in the region.

The standard sites of scorpion stings are limbs especially, hands and feet. Mainly, scorpion stings in feet occur in men due to accidental encounters with scorpions while individuals removing their shoes. Concerning our survey, about $51.1 \%$ of cases were recorded in 2017, while $55.4 \%$ of cases were recorded in 2018 in both sexes. The hospital file has documented $48.9 \%$ scorpion-stung men and $44.6 \%$ scorpion-stung women in 2018. Consequently, the male rate exceeded the female rate during all seasons for both years.

High incidence men cases were found in Erbil city followed by Duhok and Sulymaniyah and the second ratio referred to women in the same arrangement as above (Table 2). For women, most frequent sites of biting were hands due to daily house activities such as cleaning, squeezing clothes and gardening. Also, there were uncommon body scorpion sting sites such as trunk, head and neck indicating that these stings happened while they were sleeping. However, there was no a significant difference between the number of

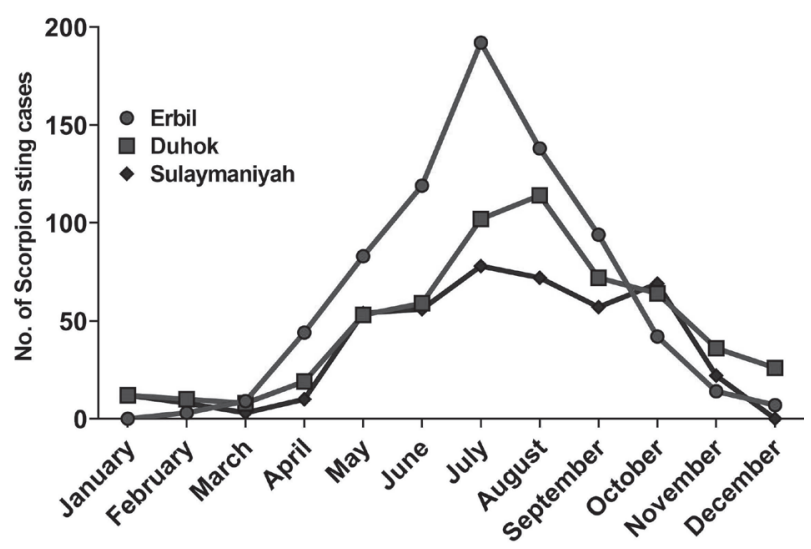

Fig. 2. Scorpion sting monthly flexural during 2017 in three cities north of Iraq.

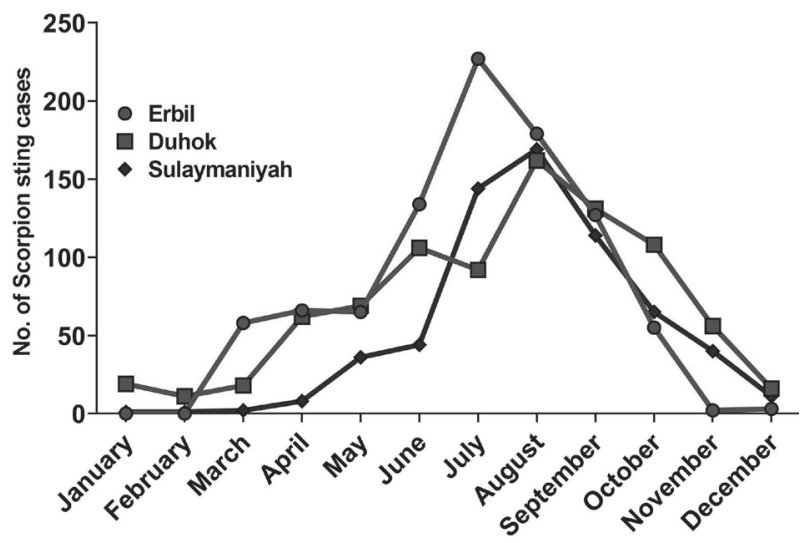

Fig. 3. Scorpion sting monthly flexural during 2018 in three cities north of Iraq. 
Table 3. Seasonal average of scorpion stings in Kurdistan -Iraq during 2017-2018.

\begin{tabular}{|c|c|c|c|c|}
\hline \multirow{2}{*}{ Year } & \multicolumn{4}{|c|}{ Seasons } \\
\cline { 2 - 5 } & Spring & Summer & Autumn & Winter \\
\hline 2017 & 283 & 930 & 470 & 78 \\
\hline 2018 & 384 & 1257 & 698 & 62 \\
\hline Total & 667 & 2187 & 1168 & 140 \\
\hline No.\% & 16.4 & 52.54 & 28.06 & 3.36 \\
\hline
\end{tabular}

scorpion sting cases in all months of the year, but the incidence peak elevated in June, July and August in all included provinces. The statistical analysis showed that the highest rate of scorpion stings in Erbil province occurred in July but for two other cities that occurred in August while the lowest ratio of scorpion stings found in January and February for all reported cases in the region (Fig. 2 and 3).

Scorpion stings for both years remain constant during seasonal distribution in which the highest incidence of scorpion sting cases occurred in summer (52.54\%) followed by fall (28.06\%), spring (16.4\%) and winter (3.36\%) in the three cities of the region (Table 3).

An equal distribution between different ages was estimated for both years, the average age of the patients was 34 years old (range 1 - above 50 years old). The highest Scorpion stings have been mostly seen in patients between 15-49 years old in which estimated about $49.7 \%$, while sting incidence for children between $0-5$ years nearly $6.4 \%$. The patients with six to 15 years old had a rate of $24.19 \%$ only and $19.6 \%$ of scorpion stings can be seen in the people older than 50 years in this series (Table 4).

\section{Discussion}

Scorpion envenomation is a major public health concern in Kurdistan region of Iraq. This region includes Erbil, Duhok and Sulaymaniyah provinces. The results of the present study indicated that 4162 scorpion stings were recorded in the public medical centers of Kurdistan region of Iraq during two years of research.
The scorpion- stung patients that attended general hospital in 2017 were less than the cases in 2018 (1761), the majority of sting found in Erbil province followed by Duhok and Sulaymaniyah This rate matches the results of [19] who have studied scorpion stings in Buenos Aires, Argentina for 14 years and they recorded highest rate of scorpion stings in 2015. Moreover Karami et al [20] studied scorpion stings in Iran for four years and they had found that the highest scorpion stings occurred in 2006.

In this study, no casualties were reported in both categories of patients; received and non-received venom anti-sera. However, only one case stated at the hospital for four days which was stung by fat tail scorpion A. crassicauda and his age forty-one years' old. AlRamahi and Al-Hasnawi [3] reported that the most frequent rampancy of scorpion stings occurring in the middle parts of Iraq are concentrated in Babylon, Najaf and Diwaniyah provinces and they are caused by $A$. crassicauda. The treatment of scorpion envenomation is based mainly on supportive care, symptomatic relief and the use of specific anti-venom serum [21].

In the present study, hands followed by feet had maximum rate for scorpion stings than other parts of the body. Many other researchers have confirmed that the high ratio of cases occurs in the upper and lower limbs. Scorpion stings at the other parts of the body such as trunk, chest head and neck mostly occur during relaxation or sleeping, also a group of scientist in Morocco has obtained the same result [22].

The results of this study showed a disparity between scorpion stings of males (51.1 .55.4\%) and females (48.9, $44.6 \%$ ) between patients who attended governmental hospitals in the abovesaid provinces for both years. So the result indicated that scorpionism among men was more frequent than the women, this means that in this region the males were at higher risk of scorpion stings than females, a similar result was found in India [23], They reported that the scorpion stung people were males (63.6\%)and females (36.4\%). Also in Argentina scorpion- stung patients were $54 \%$ males and $46 \%$ females [19] .However, it is not consistent with the results of [20] in Ramhormoz, South-West of Iran, they reported more numbers of females than males. Shahi, Moosavy [24] reported that scorpionism in Bandar Abbas between males and females nearly was equal. It is

Table 4. Frequency of scorpion stings according to age groups in Erbil, Duhok and Sulaymaniyah during 2017-2018.

\begin{tabular}{|c|c|c|c|c|c|c|c|}
\hline \multirow{2}{*}{ Age range } & \multicolumn{3}{|c|}{2017} & \multicolumn{3}{|c|}{2018} & \multirow{2}{*}{ Total } \\
\hline & Erbil & Duhok & Sulaymaniyah & Erbil & Duhok & Sulaymaniyah & \\
\hline $0-4$ & 35 & 25 & 6 & 113 & 31 & 58 & 268 \\
\hline $5-14$ & 235 & 89 & 157 & 253 & 113 & 160 & 1007 \\
\hline $15-49$ & 374 & 374 & 198 & 326 & 572 & 226 & 2070 \\
\hline $50<$ & 104 & 87 & 80 & 221 & 134 & 191 & 817 \\
\hline \multicolumn{7}{|c|}{ Total } & 4162 \\
\hline
\end{tabular}


due to different approaches and geographical positions in the two studies. The scorpion sting epidemiology is related to the victim's gender, year and location of various studies. It may, however, take cultural factors such as different female and male behaviors.

Previous studies estimated that the highest scorpion stings had occurred in hot months, mostly in the summer season [11, 20], also our result of the study indicated that scorpion stings were dominated mostly in the summer season with a peak in July and August. Some other studies showed that $49.7-93.4 \%$ of scorpion sting cases occurred in summer [25], these results are consistent with our study, where more than $52.55 \%$ of the cases were recorded in warmer months. However, data collected in the Lordegan County, southwest of Iran, reported that the highest incidence of scorpion sting cases in 2006 occurred in spring $(49.72 \%)$, but surveys in the region of Lordegan during 2002-2006 demonstrated that there was no correlation with the dominance of scorpion stings in summer or fall [26]. A critical finding of this analysis was the association between scorpion abundance and environmental factors. Low temperatures in the cold season of the study area caused low scorpion activity, but this activity gradually increases with higher temperature.

The epidemiologic research considers that scorpionism was observed mostly among the 15-49-year-olds; this age group has faced more stings than other categories. This rate is in accordance with the results of $[20,27]$. While the patient under five years old less faced with this problem. This rate matches the results of $[20,24]$. In which, the moderate ratio can be seen between the age 6-15 and patient with more than 50 years old. This rate does not differ with the results of [28]. The high rate of scorpion stings among victims younger than 30 may be explained by the fact that the majority of stings occur during work. Most outdoor activities are correlated with this age category.

Finally, based on the current results, scorpionism is a hard consequence health issue in the Kurdistan regionIraq, in term of relations with all age's categories and both sexes and with a large number of stung patients, but this matter is not entirely realized by people and public health organizations, so increasing information about prevention methods of scorpion stings is recommended.

\section{Conclusions}

Scorpion sting is one of Iraq's oldest health issues. It has been concluded that the scorpion stings in the Kurdistan region of Iraq are epidemiologically similar to other studies conducted elsewhere. Regarding to the parameters incorporated in our survey such as age, sex, sting site, scorpion species and seasonal frequency, the findings of the current study are approximately similar to that results recorded in Iran and Saudi Arabia. The scorpion stings ranged from 1761 cases in 2017 to 2401 cases in 2018. Epidemiologically, anti-venom injection in patients was recommended to prevent death following scorpion stings. Both hospitals and other health centers need to be well-educated and equipped with anti-venom sera to save life of scorpion-stung people. This database should be yearly revised based on the updated field. Regular educational programs in rural and urban areas are also mandatory to increase people's understanding and awareness of the biology of scorpions, hazardous species and the accidents they cause and how to treat such cases.

\section{Acknowledgements}

The authors are grateful indeed to staffs of provincial health centers in Erbil, Duhok and Sulaymaniyah for their cooperation and generous help.

\section{Conflict of Interest}

The authors attest that there is no any conflict of interest regarding contents of this manuscript.

\section{References}

1. ŠŤÁHLAVSKÝ F., ŠTUNDLOVÁ J., LOWE G., STOCKMANN M., KOVAŘ́́K F. Application of cytogenetic markers in the taxonomy of flat rock scorpions (Scorpiones: Hormuridae), with the description of Hadogenes weygoldti sp. n. Zoologischer Anzeiger. 273, 173, 2018.

2. KASSIRI H., KASIRI A., KASIRI E., ABDIAN P., MATORI F., LOTFI M. Epidemiological characteristics and incidence rate of definite scorpion stings in Mahshahr County, Iran: multivariate analysis of 1635 cases. Asian Pacific Journal of Tropical Disease. 5 (1), 80, 2015.

3. AL-RAMAHI H.M., AL-HASNAWI M.H. Diagnostic and epidemiologic Study of fat tail scorpion (Androctonus crassicuada) in Mid-Euphrates region/Iraq. journal of kerbala university. 10 (1), 263, 2012.

4. TAN H.H., MONG R. Scorpion stings presenting to an emergency department in Singapore with special reference to Isometrus maculatus. Wilderness \& environmental medicine. 24 (1), 42, 2013.

5. ABROUG F., OUANES-BESBES L., TILOUCHE N. ELATROUS S. Scorpion envenomation: state of the art. Intensive care medicine. 1-10, 2020.

6. KASSIRI H., KASIRI N., DIANAT A. Species composition, sex ratio, geographical distribution, seasonal and monthly activity of scorpions and epidemiological features of scorpionism in Zarrin-dasht County, Fars Province, Southern Iran. Asian Pacific Journal of Tropical Disease. 5, S99-S103, 2015.

7. CHIPPAUX J.P., GOYFFON M. Epidemiology of scorpionism: a global appraisal. Acta tropica. 107 (2), 71, 2008.

8. CUPO P. Clinical update on scorpion envenoming. Revista da Sociedade Brasileira de Medicina Tropical. 48, 642, 2015.

9. IQBAL M.A., GUPTA M. Cardiogenic Pulmonary Edema. StatPearls [Internet]. StatPearls Publishing. 2019. 
10. URTEAGA-REYESVERA J.C., POSSANI-ESPINOSA A. Scorpions: Classification of poisonous species using shape features. in 2016 International Conference on Electronics, Communications and Computers (CONIELECOMP). IEEE, 2016.

11. KHATONY A., ABDI A., FATAHPOUR T., TOWHIDI F. The epidemiology of scorpion stings in tropical areas of Kermanshah province, Iran, during 2008 and 2009. Journal of venomous animals and toxins including tropical diseases. 21 (1), 45, 2015.

12. SISSOM W.D., FET V. Redescription of compsobuthus matthiesseni (scorpiones, buthidae) from southwestern Asia. Journal of Arachnology. 1998, 1, 1998.

13. FET V., KOVAŘ́IK F. First record of euscorpius (polytrichobothrius) italicus (scorpiones: euscorpiidae) from iraq. Acta Soc. Zool. Bohem. 67, 179, 2003.

14. TAHIR H.M., NAVIDPOUR S., PRENDINI L. First reports of Razianus (Scorpiones: Buthidae) from Iraq and Pakistan, descriptions of two new species, and redescription of Razianus zarudnyi. American museum novitates. 2014 (3806), 1, 2014.

15. AHMED S.T. Morphology And Histology Of Venom Gland Of Scorpio Maurus Kruglovi (Birula, 1910) (Scorpionidae: Scorpiones). Zanco Journal of Pure and Applied Sciences. 27 (5), 59, 2015.

16. AL-AZAWII Z. Description of new species of scorpions Compsobuths iragnsis, (Arachnida: Buthidae) for the first time on Iraq and world. Iraqi Journal of Agricultural Sciences. 49 (4), 2018.

17. KORZENIEWSKI K. The epidemiological situation in Iraq. Przeglad epidemiologiczny. 60 (4), 845, 2006.

18. MAULOOD B., HINTON G. Observation on the algal flora of Sulaimani area (1) green and blue algae Zanco. Seeies A. 4 (1), 55, 1978.

19. FERNANDEZ M.L., LLOVERAS S.C., FALCONE C.C., GONZALEZ G.D., GARRO S.L., ECHAZARRETA S.E., MARTINO O.A., ORDUNA T.A. Scorpion stings in Buenos Aires, Argentina: Epidemiological and clinical aspects. Acta toxicológica argentina. 26 (1), 2018.

20. KARAMI K., VAZIRIANZADEH B., MASHHADI E., HOSSIENZADEH M., ABBAS MORAVVEJ S. A
Five Year Epidemiologic Study on Scorpion Stings in Ramhormoz, South-West of Iran. Pakistan Journal of Zoology. 45 (2), 2013.

21. BOSNAK M., ECE A., YOLBAS I., BOSNAK V., KAPLAN M., GURKAN F. Scorpion sting envenomation in children in southeast Turkey. Wilderness \& environmental medicine. 20 (2), 118, 2009.

22. ABOURAZZAK S., ACHOUR S., EL ARQAM L., ATMANI S., CHAOUKI S., SEMLALI I., SOULAYMANI BENCHEIKH R., BOUHARROU A., HIDA M. Epidemiological and clinical characteristics of scorpion stings in children in Fez, Morocco. Journal of venomous animals and toxins including tropical diseases. 15 (2), 255, 2009

23. RAJASHEKHAR., MUDGAL S.M. Epidemiological and Clinical Study of Scorpion Envenomation in Patients Admitted at Rims Teaching Hospital, Raichur. International Journal of Scientific Study. 5 (3), 73, 2017.

24. SHAHI M., MOOSAVY S.H., HANAFI-BOJD A.A., NAVIDPOUR S., ZARE S., MADANI A., RAFINEJAD J. Spatial distribution of scorpion sting in a high-risk area of southern Iran. Journal of medical entomology. 53 (5), 1198, 2016.

25. MOLAEE S.M., AHMADI K.A., VAZIRIANZADEH B., MORAVVEJ S.A. A climatological study of scorpion sting incidence from 2007 to 2011 in the Dezful area of Southwestern Iran, using a time series model. Journal of Insect Science. 14 (1), 2014.

26. VAZIRIANZADEH B., HOSSIENZADEH M., MORAVVEJ S., VAZIRIANZADEH M., MOSAVI S. An epidemiological study on scorpion stings in Lordegan County, south-west of Iran. 2013.

27. BARROS R.M., PASQUINO J.A., PEIXOTO L.R., TARGINO I.T.G., SOUSA J.A.D., LEITE R.D.S. Clinical and epidemiological aspects of scorpion stings in the northeast region of Brazil. Ciencia \& saude coletiva. 19, 1275, 2014.

28. JARRAR B.M., Al-ROWAILY M.A. Epidemiological aspects of scorpion stings in Al-Jouf province, Saudi Arabia. Annals of Saudi medicine. 28 (3), 183, 2008. 